\title{
Testing the Product Test
}

\author{
H. Brea, E. Grifell-Tatjé and C. A. K. Lovell*
}

CEPA, School of Economics, University of Queensland, Brisbane QLD 4072, Australia

\begin{abstract}
The product test asks the product of volume and price index numbers to equal the corresponding value change. The literature treats the product test as a requirement. We treat it as a hypothesis, and we provide an empirical test.
\end{abstract}

This is a postprint version of the article that was published in

H. Brea, E. Grifell-Tatjé and C.A.K. Lovell, (2011), Economics Letters vol.113, issue 2, November, pp. 157-159.

DOI: $10.1016 /$ j.econlet.2011.06.017

JEL classification: D24, 047

Keywords: product test, index numbers

*Corresponding author. Tel.: +61 73365 6570; fax +61 733657299.

E-mail addresses: humberto.brea@uab.cat (Brea), emili.grifell@uab.cat (GrifellTatjé), k.lovell@uq.edu.au (Lovell) 
H. Brea, E. Grifell-Tatjé and C.A.K. Lovell, (2011), Economics Letters vol.113, issue 2, November, pp. 157-159. [DOI: 10.1016/j.econlet.2011.06.017]

\section{Testing the Product Test}

\section{Introduction}

Consider a value ratio, the observed magnitude of which Fisher $(1922 ; 75)$ called "indubitable and undebatable." Fisher continued "...[T]he problem then is to find a form of index number such that, applied alike to prices and quantities, it shall correctly 'factor' any such value ratio." This is Fisher's factor reversal test, a stringent test because it requires the product of a price index and a volume index of the same functional form to equal the value ratio. Noting that so few functional forms satisfy the factor reversal test, Fisher proposed using the test not just as a screening device, but also as a way of deriving implicit index numbers: dividing a value ratio by a price (volume) index generates an implicit volume (price) index, and both pairs satisfy the factor reversal test by construction.

Frisch (1930), noting the restrictiveness of the factor reversal test, introduced a weaker product test, which requires that the product of a price and volume index equal the value ratio, without requiring that the indexes have the same functional form. Even this weakened product test is too challenging for several popular index number pairs, including Edgeworth-Marshall and Törnqvist.

However the failure of an index number pair to satisfy the product test may be acceptably small or unacceptably large. Particularly if an index number pair has desirable properties, it may be appropriate to treat satisfaction of the product test as a hypothesis to be tested rather than a condition to be imposed. Our objective is to conduct a statistical test of the hypothesis that desirable volume and price indexes, which fail the product test, fail to a statistically acceptable degree. We conduct the test using Malmquist volume indexes and Fisher price indexes. The desirability of a Malmquist volume index is based on its satisfaction of a number of theoretical properties enumerated by Balk (1998), and its decomposability into the product of economic drivers of volume change (e.g., efficiency change and technical change). The desirability of a Fisher price index is based on its being a superlative index, as demonstrated by Diewert (1992), and its additive and multiplicative decomposability into the weighted sum or product of individual price changes.

We test the product test using a panel of prices and volumes in US agriculture. We conduct the test within a framework that expresses profitability change as the product of productivity change, the ratio of an output volume index and an input volume index, and price recovery change, the ratio of an output price index and an input price index. The hypotheses that the product test is satisfied for output prices and volumes, and for input prices and volumes, are not rejected. However the hypothesis that the product test is satisfied for productivity change and price recovery change is rejected. In all three cases the extent of failure is numerically small.

\section{Profitability Change and the Product Test}

We use profitability, the ratio of revenue to cost, as an indicator of financial performance. Profitability is less popular than profit, but it has a long history as a financial performance indicator. Bliss (1923) recommended its use over long time 
H. Brea, E. Grifell-Tatjé and C.A.K. Lovell, (2011), Economics Letters vol.113, issue 2, November, pp. 157-159. [DOI: 10.1016/j.econlet.2011.06.017]

periods because fluctuations in prices are likely to cancel out of numerator and denominator. Davis (1947) treated profitability as an indicator of the efficiency with which business converts expenditure to revenue. Georgescu-Roegen (1951) noted its independence of the scale of production, a desirable property not shared by profit.

Let $\mathrm{R}=\Sigma \mathrm{p}_{\mathrm{m}} \mathrm{y}_{\mathrm{m}}$ denote revenue and $\mathrm{C}=\Sigma \mathrm{w}_{\mathrm{n}} \mathrm{x}_{\mathrm{n}}$ denote cost, and define $\Pi=$ $\mathrm{R} / \mathrm{C}$ as profitability. Change in profitability from base year 0 to comparison year 1 is

$$
\Pi^{1} / \Pi^{\circ}=\left(R^{1} / R^{\circ}\right) /\left(C^{1} / C^{\circ}\right) \text {. }
$$

Values $\mathrm{R}$ and $\mathrm{C}$ change because volumes change and prices change, and we want to convert (1) to an expression showing profitability change as the product of productivity change and price recovery change.

For outputs we seek price and volume indexes such that

$$
R^{1} / R^{0}=P\left(p^{1}, p^{0}, \bullet\right) \times Y\left(y^{1}, y^{0}, \bullet\right)
$$

and for inputs we seek price and volume indexes such that

$$
\mathrm{C}^{1} / \mathrm{C}^{\circ}=\mathrm{W}\left(\mathrm{w}^{1}, \mathrm{w}^{\circ}, \bullet\right) \times \mathrm{X}\left(\mathrm{x}^{1}, \mathrm{x}^{0}, \bullet\right)
$$

where we are deliberately vague about the remaining arguments of the four indexes. If both equalities hold, then

$$
\Pi^{1} / \Pi^{0}=\left[Y\left(y^{1}, y^{0}, \bullet\right) / X\left(x^{1}, x^{0}, \bullet\right)\right] \times\left[P\left(p^{1}, p^{0}, \bullet\right) / W\left(w^{1}, w^{0}, \bullet\right)\right]
$$

which meets our objective of expressing profitability change as the product of productivity change and price recovery change.

However equalities (2) and (3) do not necessarily hold. If price indexes have Konüs form, then $\mathrm{P}\left(\mathrm{p}^{1}, \mathrm{p}^{0}, \bullet\right)=\mathrm{P}_{\mathrm{K}}\left(\mathrm{p}^{1}, \mathrm{p}^{0}, \mathrm{x}^{1}, \mathrm{x}^{0}\right)$ and $\mathrm{W}\left(\mathrm{w}^{1}, \mathrm{w}^{0}, \bullet\right)=\mathrm{W}_{\mathrm{K}}\left(\mathrm{w}^{1}, \mathrm{w}^{0}, \mathrm{y}^{1}, \mathrm{y}^{0}\right)$, and if volume indexes have Malmquist form, then $Y\left(\mathrm{y}^{1}, \mathrm{y}^{0}, \bullet\right)=\mathrm{Y}_{\mathrm{M}}\left(\mathrm{y}^{1}, \mathrm{y}^{0}, \mathrm{x}^{1}, \mathrm{x}^{0}\right)$ and $\mathrm{X}\left(\mathrm{x}^{1}, \mathrm{x}^{0}, \bullet\right)$ $=X_{M}\left(x^{1}, x^{0}, y^{1}, y^{0}\right)$, but neither equality holds. Our best theoretical indexes fail the product test. If price and volume indexes have Törnqvist form, then $P\left(p^{1}, p^{0}, \bullet\right)=$ $P_{\mathrm{T}}\left(\mathrm{p}^{1}, \mathrm{p}^{0}, \mathrm{y}^{1}, \mathrm{y}^{0}\right), \quad \mathrm{W}\left(\mathrm{w}^{1}, \mathrm{w}^{0}, \bullet\right)=\mathrm{W}_{\mathrm{T}}\left(\mathrm{w}^{1}, \mathrm{w}^{0}, \mathrm{x}^{1}, \mathrm{x}^{0}\right), \quad \mathrm{Y}\left(\mathrm{y}^{1}, \mathrm{y}^{0}, \bullet\right)=\mathrm{Y}_{\mathrm{T}}\left(\mathrm{y}^{1}, \mathrm{y}^{0}, \mathrm{p}^{1}, \mathrm{p}^{0}\right)$ and $\mathrm{X}\left(\mathrm{X}^{1}, \mathrm{X}^{0}, \bullet\right),=\mathrm{X}_{\mathrm{T}}\left(\mathrm{X}^{1}, \mathrm{X}^{0}, \mathrm{w}^{1}, \mathrm{w}^{0}\right)$, but neither equality holds. One of our best empirical indexes fails the product test. If price and volume indexes have Fisher form, both equalities hold and expression (4) provides an exact decomposition of profitability change.

For reasons mentioned above, we prefer to pair Fisher price indexes with Malmquist volume indexes. However these pairings fail the product test, which we express as

$$
\begin{aligned}
& R^{1} / R^{\circ} \neq P_{F}\left(p^{1}, p^{\circ}, y^{1}, y^{\circ}\right) \times Y_{M}\left(y^{1}, y^{\circ}, x^{1}, x^{\circ}\right), \\
& C^{1} / C^{\circ} \neq W_{F}\left(w^{1}, w^{0}, x^{1}, x^{\circ}\right) \times X_{M}\left(x^{1}, x^{\circ}, y^{1}, y^{\circ}\right),
\end{aligned}
$$


H. Brea, E. Grifell-Tatjé and C.A.K. Lovell, (2011), Economics Letters vol.113, issue 2, November, pp. 157-159. [DOI: 10.1016/j.econlet.2011.06.017]

and consequently

$$
\Pi^{1} / \Pi^{0} \neq\left[Y_{M}\left(y^{1}, y^{0}, x^{1}, x^{0}\right) / X_{M}\left(x^{1}, x^{0}, y^{1}, y^{0}\right)\right] \times\left[P_{F}\left(p^{1}, p^{0}, y^{1}, y^{0}\right) / W_{F}\left(w^{1}, w^{0}, x^{1}, x^{0}\right)\right],
$$

which states that profitability change cannot be expressed as the product of a Malmquist productivity index and a Fisher price recovery index.

However we have theoretical and empirical reasons to expect the failures in (5) - (7) to be acceptably small. Balk (1998) collects two sets of results. The first relies on a flexible specification of production technology, and on allocative efficiency, to obtain $Y_{M}\left(y^{1}, y^{0}, x^{1}, x^{0}\right)=Y_{F}\left(y^{1}, y^{0}, p^{1}, p^{0}\right)$ and $X_{M}\left(x^{1}, x^{0}, y^{1}, y^{0}\right)=$ $X_{F}\left(x^{1}, x^{0}, w^{1}, w^{0}\right)$. Both product tests are exactly satisfied, but under functional form and allocative efficiency restrictions. The second, based on Mahler's inequality, yields $\mathrm{Y}_{\mathrm{M}}\left(\mathrm{y}^{1}, \mathrm{y}^{0}, \mathrm{x}^{1}, \mathrm{x}^{0}\right) \approx \mathrm{Y}_{\mathrm{F}}\left(\mathrm{y}^{1}, \mathrm{y}^{0}, \mathrm{p}^{1}, \mathrm{p}^{0}\right)$ and $\mathrm{X}_{\mathrm{M}}\left(\mathrm{x}^{1}, \mathrm{x}^{0}, \mathrm{y}^{1}, \mathrm{y}^{0}\right) \approx \mathrm{X}_{\mathrm{F}}\left(\mathrm{x}^{1}, \mathrm{x}^{0}, \mathrm{w}^{1}, \mathrm{w}^{0}\right)$. Both product tests are approximately satisfied, the approximation error depending on the extent of resource misallocation. This generates an alternative interpretation of the tests: tests of the product test in (5) - (7) are also tests of equality between theoretical Malmquist volume indexes and their empirical Fisher counterparts.

Fisher price indexes are calculated, and Malmquist volume indexes are estimated, from observed data. Whatever we know about (5) - (7) is compounded by estimation error. Referring to the result based on Mahler's inequality, estimation error may moderate or exacerbate optimization error. An empirical test of the product test is needed.

\section{Testing the Product Test}

We test the product test using a panel of agriculture production in 48 US states during 1960-2004, as described in Ball et al. (2004). The data include price and volume indexes for three outputs (livestock, crops and other output) and four inputs (capital, land, labor and materials). We calculate value ratios $R^{1} / R^{\circ}$ and $C^{1} / C^{\circ}$ and price indexes $P_{F}\left(p^{1}, p^{0}, y^{1}, y^{0}\right)$ and $W_{F}\left(w^{1}, w^{0}, x^{1}, x^{0}\right)$ directly from the data, and we use linear programming techniques to estimate volume indexes $Y_{M}\left(y^{1}, y^{0}, x^{1}, x^{0}\right)$ and $\mathrm{X}_{\mathrm{M}}\left(\mathrm{x}^{1}, \mathrm{x}^{0}, \mathrm{y}^{1}, \mathrm{y}^{0}\right)$.

We base our statistical tests on the ratios of the left side to the right side of (5) - (7). The output product test approximation error is defined from (5) as $\varepsilon_{Y}=\left(R^{1} / R^{\circ}\right) /$ $\left[Y_{M}\left(y^{1}, y^{0}, x^{1}, x^{0}\right) \times P_{F}\left(p^{1}, p^{0}, y^{1}, y^{0}\right)\right]$. Under the null hypothesis of no output product test approximation error, $\varepsilon_{Y}$ is a unit vector. We apply the same strategy to (6) and (7).

\section{Insert Table 1 About Here}

The evidence summarized in Table 1, based on 2,112 observations, is encouraging. It is not possible to reject, at a $95 \%$ confidence level, either of the product test hypotheses $\left(\mathrm{R}^{1} / \mathrm{R}^{0}\right)=\left[\mathrm{Y}_{\mathrm{M}}\left(\mathrm{y}^{1}, \mathrm{y}^{0}, \mathrm{x}^{1}, \mathrm{x}^{0}\right) \times \mathrm{P}_{\mathrm{F}}\left(\mathrm{p}^{1}, \mathrm{p}^{0}, \mathrm{y}^{1}, \mathrm{y}^{0}\right)\right]$ and $\mathrm{C}^{1} / \mathrm{C}^{0}=$ $W_{F}\left(w^{1}, w^{0}, x^{1}, x^{0}\right) \times X_{M}\left(x^{1}, x^{0}, y^{1}, y^{0}\right)$. It follows that estimated Malmquist volume indexes provide excellent approximations to calculated Fisher volume indexes. This is a 
H. Brea, E. Grifell-Tatjé and C.A.K. Lovell, (2011), Economics Letters vol.113, issue 2, November, pp. 157-159. [DOI: 10.1016/j.econlet.2011.06.017]

reversal of the usual line of reasoning, which states that Fisher volume indexes provide approximations to their theoretical Malmquist counterparts. However our estimate of $Y_{M}\left(x^{1}, x^{0}, y^{1}, y^{0}\right)$ has smaller mean than that of $Y_{F}\left(y^{1}, y^{0}, p^{1}, p^{0}\right)$, and our estimate of $X_{M}\left(y^{1}, y^{0}, x^{1}, x^{0}\right)$ has larger mean than that of $X_{F}\left(x^{1}, x^{0}, w^{1}, w^{0}\right)$. This makes it possible to reject the hypothesis that $Y_{M}\left(x^{1}, x^{0}, y^{1}, y^{0}\right) / X_{M}\left(x^{1}, x^{0}, y^{1}, y^{0}\right)=$ $Y_{F}\left(y^{1}, y^{0}, p^{1}, p^{0}\right) / X_{F}\left(x^{1}, x^{0}, w^{1}, w^{0}\right)$ at the same confidence level.

From a statistical perspective, our evidence is mixed: estimated Malmquist volume indexes satisfy the product test with Fisher price indexes, although an estimated Malmquist productivity index does not satisfy the product test with a Fisher price recovery index. However the mean product test approximation error is extremely small, less than $0.4 \%$, probably far smaller than what Fisher (1922) calls the formula error associated with the Fisher price recovery index and the estimation error associated with the Malmquist productivity index. In light of the importance we attach to our dual objective of decomposing a Malmquist productivity index by economic driver and decomposing a Fisher price recovery index by individual price change, we are willing to live with a $0.4 \%$ product test approximation error.

\section{Conclusions}

Most researchers are, by necessity, not purists. They have come to accept formula error associated with the use of empirical index numbers, although they prefer superlative index numbers because under certain conditions they provide closer approximations to the truth than other index numbers do. They also accept estimation error associated with econometric or mathematical programming estimates of the truth, although they attempt to minimize estimation error through the specification of functional form and estimation technique. We are willing to live with a third type of error, which we call product test approximation error, which we attempt to minimize by pairing our best theoretical volume indexes with our best empirical price indexes.

We have provided one piece of empirical evidence bearing on the magnitude of the product test approximation error. We fail to reject the hypothesis of no product test approximation error on the revenue side and on the cost side, but we do reject the hypothesis at the profitability level. In all three cases the approximation error is numerically small.

One interpretation of our findings is that empirical estimates of theoretical indexes are, statistically and numerically, close to calculated values of their empirical counterparts. This interpretation provides a reverse spin on the superlative index number literature. An alternative interpretation is that if one has good reason for preferring a pair of indexes that fail the product test (and the Malmquist/Fisher pairing clearly qualifies), then one might well be willing to live with the resulting product test approximation error.

Fisher preferred his index number because it satisfies his set of tests. However it fails the important circularity test. It is worth quoting Fisher on this embarrassment: "I aim to show that the circular test is theoretically a mistaken one, that a necessary irreducible minimum of divergence from such fulfillment is entirely right and proper, and, therefore, that a perfect fulfillment of this so-called circular test 
H. Brea, E. Grifell-Tatjé and C.A.K. Lovell, (2011), Economics Letters vol.113, issue 2, November, pp. 157-159. [DOI: 10.1016/j.econlet.2011.06.017]

should really be taken as proof that the formula which fulfils it is erroneous." (p. 271, italics in the original)

Applying Fisher's unwillingness to require exact fulfilment of the circular test to the product test, we suggest that "...a necessary irreducible minimum of divergence from such fulfilment is entirely right and proper...."

\section{References}

Balk, B. M., 1998, Industrial Price, Quantity, and Productivity Indexes. (Kluwer Academic Publishers, Boston).

Ball, V. E., C. Hallahan and R. Nehring, 2004, Convergence of Productivity: An Analysis of the Catch-up Hypothesis within a Panel of States, American Journal of Agricultural Economics 86, 1315-1321.

Bliss, J. H., 1923, Financial and Operating Ratios in Management. (The Ronald Press Co., New York).

Davis, H. S., 1947, The Industrial Study of Economic Progress. (University of Pennsylvania Press, Philadelphia).

Diewert, W. E., 1992, Fisher Ideal Output, Input, and Productivity Indexes Revisited, Journal of Productivity Analysis 3, 211-248.

Fisher, I., 1922, The Making of Index Numbers. (Houghton Mifflin, Boston).

Frisch, R., 1930, Necessary and Sufficient Conditions Regarding the Form of an Index Number which Shall Meet Certain of Fisher's Tests, Journal of the American Statistical Association 25, 397-406.

Georgescu-Roegen, N., 1951, The Aggregate Linear Production Function and its Applications to von Neumann's Economic Model, in: T. C. Koopmans, ed., Activity Analysis of Production and Allocation. (John Wiley \& Sons, New York) 98-115.

\begin{tabular}{|l|c|c|c|}
\hline & $\begin{array}{c}\varepsilon_{Y}=\mathrm{R}^{1} / \mathrm{R}^{\circ} / \\
\mathrm{Y}_{\mathrm{M}} \times \mathrm{P}_{\mathrm{F}}\end{array}$ & $\begin{array}{c}\varepsilon_{\mathrm{X}}=\mathrm{C}^{1} / \mathrm{C}^{\circ} / \\
\mathrm{X}_{\mathrm{M}} \times \mathrm{W}_{\mathrm{F}}\end{array}$ & $\begin{array}{c}\varepsilon_{Y} / \varepsilon_{\mathrm{X}}=\Pi^{1} / \Pi^{\circ} / \\
\mathrm{Y}_{\mathrm{M}} / \mathrm{X}_{\mathrm{M}} \times\left(\mathrm{P}_{\mathrm{F}} / \mathrm{W}_{\mathrm{F}}\right)\end{array}$ \\
\hline Mean & 1.0014 & 0.9987 & 1.0041 \\
\hline Standard Dev. & 0.0501 & 0.0391 & 0.0616 \\
\hline Maximum & 1.3175 & 1.2484 & 1.3461 \\
\hline Minimum & 0.6072 & 0.8425 & 0.6160 \\
\hline Observations & 2,112 & 2,112 & 2,112 \\
\hline 95\% Conf. Int. & {$[1.0035,0.9992]$} & {$[1.0004,0.9970]$} & {$[1.0058,1.0015]$} \\
\hline
\end{tabular}

Table 1. Statistical Tests of the Product Test Approximation Error 